\title{
A viral system to optimise the daily drayage problem
}

\section{Alejandro Escudero-Santana*, Pablo Cortés, Jesús Muñuzuri and Pablo Aparicio} \author{
Universidad de Sevilla, \\ Seville, Spain \\ Email: alejandroescudero@us.es \\ Email: pca@us.es \\ Email: munuzuri@us.es \\ Email: pabloaparicio@us.es \\ *Corresponding author
}

Departamento de Organización Industrial y Gestión de Empresas II,

\begin{abstract}
The intermodal transport chain can become more efficient by means of a good organisation of the drayage movements. Drayage in intermodal container terminals involves the pick up or delivery of containers at customer locations, and the main objective is normally the assignment of transportation tasks to the different vehicles, often with the presence of time windows. This paper focuses on a new approach to tackle the daily drayage problem by the use of viral system (VS). VS is a novel bio-inspired approach that makes use of a virus-infection biological analogy that is producing very satisfactory results when dealing with complex problems with huge feasibility region.
\end{abstract}

Keywords: viral system; bio-inspired optimisation; drayage; intermodality.

Reference to this paper should be made as follows: Escudero-Santana, A., Cortés, P., Muñuzuri, J. and Aparicio, P. ( $\mathrm{xxxx)}$ 'A viral system to optimise the daily drayage problem', Int. J. Bio-Inspired Computation, Vol. $\mathrm{x}$, No. $\mathrm{x}, \mathrm{pp} . \mathrm{xxx}-\mathrm{xxx}$.

Biographical notes: Alejandro Escudero-Santana received his $\mathrm{PhD}$ in Engineering from the University of Seville. He is an Associate Professor at the Department of Industrial Management and Business II, University of Sevilla. His research interests include issues related to transportation, logistic, and the optimisation of process through the information technologies.

Pablo Cortés is a Professor at the University of Seville and Manager of Andalusian Association for Research and Industrial Cooperation. He received his BSc in Industrial Engineering from the University of Seville and $\mathrm{PhD}$ in Organisation Engineering from the University of Seville. His main fields of work, where he has published numerous research papers in international journals and completed many R\&D projects, include logistics and transport, production management and the application of operations research to industrial engineering problems.

Jesús Muñuzuri is a Professor at the University of Seville. He received his BSc in Industrial Engineering from the University of Seville, MSc in Industrial Design and Production from the University of Wales Swansea and $\mathrm{PhD}$ in Organisation Engineering at the University of Seville. His expertise covers mainly the field of quantitative optimisation of transportation and logistic problems.

Pablo Aparicio received his $\mathrm{PhD}$ in Engineering at the University of Seville. His research interests focus on several fields like applicances of expert systems and soft computing in different areas such as transport, logistics, and comfort in buildings.

This paper is a revised and expanded version of a paper entitled 'A viral system to optimise the daily drayage problem' presented at CIO-ICIEOM-IIIE 2014, Málaga, 23-25 July 2014.

\section{Introduction}

According to Eurostat data, a tonne is moved around $25 \mathrm{~km}$, per person every day. The movement of goods is a fundamental aspect of the modern economy, and efficiency in the transport system is therefore essential for economic progress. Also, this sector has been undergoing a great growth in the last decades.
However, the increase is not proportional among different means of transport, withroad transport prevailing in the movement of freight. Due to this preference for trucks, in the movement of goods, several links of the European transport network suffer congestion effects. This increasing road congestion and the necessity to find more sustainable means of transport have encouraged different governments to promote intermodality as an alternative. 
Figure 1 VS flowchart

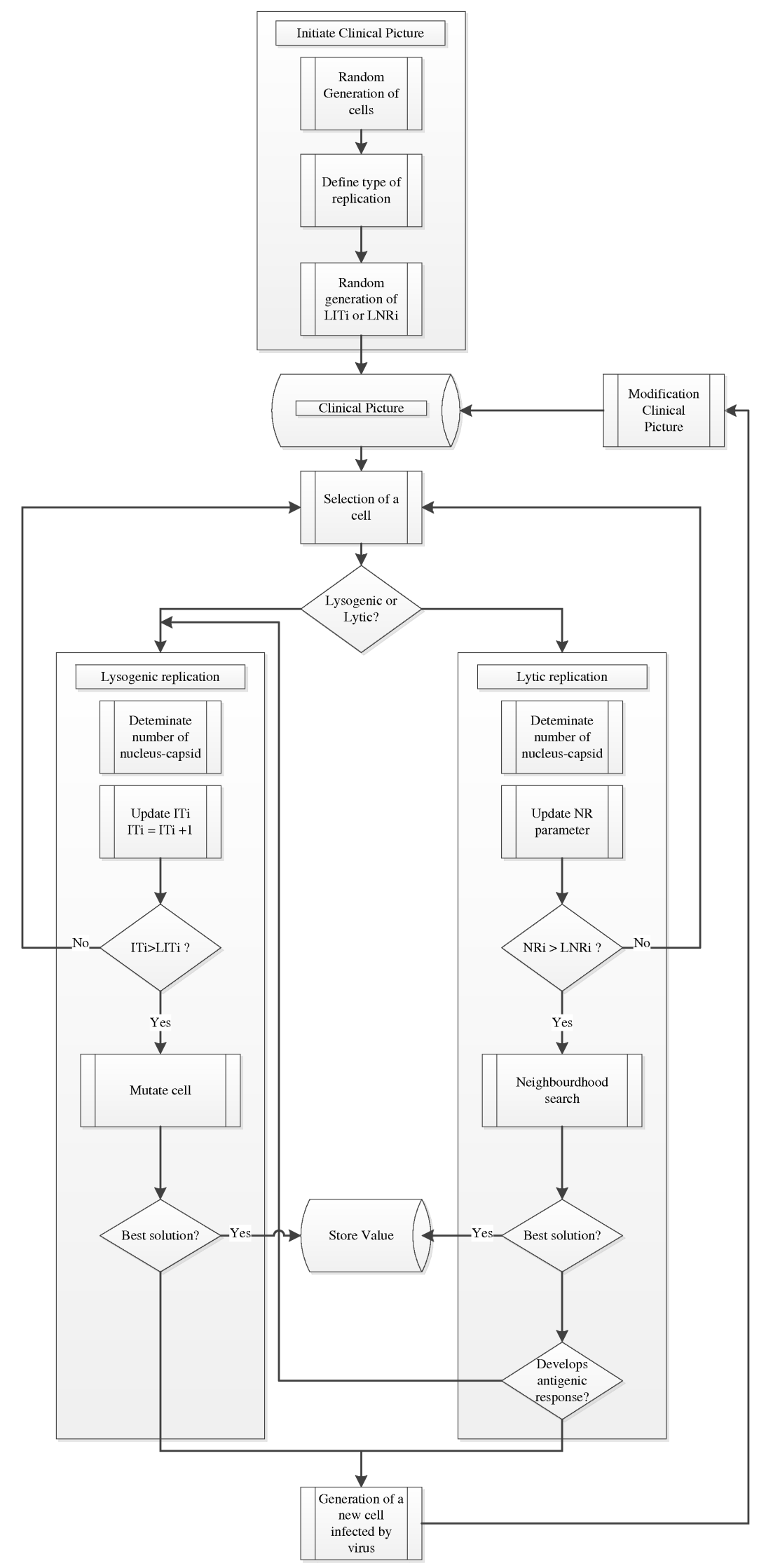


Intermodal transport combines the cost effectiveness of a principal transport (railways or ships) with the flexibility provided by trucks in the initial and final links of the transport chain. Nevertheless, this combined transport presents several difficulties related to the existence of friction cost in the transhipment nodes between different transport modes. Despite the economies of scale that can be achieved in the main transport links, these additional costs decrease the attractiveness of the overall intermodal chain.

In intermodal transport chain, the initial and final road-based trips, called drayage operations, represent more than $40 \%$ of the total transport costs. Drayage operations move loaded or empty containers between terminals, shippers and consignees. The adequate planning of drayage operations has the potential to reduce the friction cost in intermodal chains, thus raising the viability of intermodal transport.

The daily drayage problem involves the routing of vehicles to complete a set of drayage tasks. Its objective is to minimise the total cost of all the operations carried out in the hinterland of a terminal. When these tasks have to be completed under time window restrictions, the problem is called daily drayage problem with time windows (DDPTW).

The DDPTW can be considered a specific case of the vehicle routing problem with time windows, VRPTW, where the status of the truck is a binary variable: the truck can be loaded, with a container, or bobtail, without any container. This could lead to think that may think that the different approaches used to solve the VRPTW could be directly applied to the DDPTW with similar performance. However, experimental results prove that good VRPTW algorithms might not be the optimal method to solve specific DDPTW instances (Dumas et al., 1995).

Over the last years, a series of papers has focused on the deterministic DDPTW. Gronalt et al. (2003) develop four heuristics based on cost savings. This same problem is solved through Lagrangian relaxation by Imai et al. (2007) in the hinterland of a terminal. Caris and Janssens (2009) propose a two-phase insertion heuristic to build an initial solution that is then improved by a local search process. In a follow-up work (Caris and Janssens, 2010), a deterministic annealing algorithm is also included. jula et al. (2005) model the problem with time windows in origin and destination as an am-TSPTW, and suggest three solution approaches:

a an exact method based on dynamic programming

b a hybrid methodology consisting of dynamic programming for generating feasible solutions in conjunction with genetic algorithms

c a heuristic insertion method.

Namboothiri and Erera (2008) develop an understanding of the potential productivity impacts of appointment-based access control systems on drayage firms. Smilowitz (2006) and Francis et al. (2007) model the problem as an asymmetric multi travelling salesman problem
(am-TSPTW) with flexible tasks, which are used to model potential empty trailer movements. The number of possible executions of flexible tasks is limited by the distance between nodes, upon which a region of geographic feasibility is defined. Zhang et al. (2009) formulate the problem with multiple depots and a single terminal, and use a reactive tabu search to solve it. This problem is expanded in Zhang et al. (2011), who use a windows-partition-based method. Zhang et al. (2010) limit the number of empty containers in the depot, and even though this problem only considers a depot and a terminal, it is computationally more complex.

Our research is focused on solving the DDP using a novel bioinspired approach, the viral system (VS). This metaheuristic method was recently proposed by Cortes et al. (2008), and has since been applied to a large number of combinatorial problems. Valles Sosa's philosofical dissertation was devoted to this issue (Valles-Sosa, 2011). Examples of VS applications have been produced on very diverse domains such as layout problems (Ituarte-Villarreal and Espiritu, 2012; Espiritu and Ituarte-Villarreal, 2013), production problems (Santosa and Affandi, 2013; Tan and Suryadi, 2013), knapsack problems (Suryadi and Kartika, 2011), steiner problem (Cortés et al., 2010) and transport problem (Suryadi et al., 2012; Cortés et al., 2013). So, the contribution of this work is to demostrate the performance of the VS in other class of the combinatorial problem.

Section 2 shows a description of the VS method, and how it is modelled to address the DDPTW. Section 3 shows the experimental tests that were carried out, as well as the results. We conclude the paper with an analysis of this new methodological application.

\section{The VS approach}

\subsection{VS: the foundation of the bio-inspired analogy}

VS constitute a bio-inspired algorithm based on the behaviour of a specific type of viruses called phages. Phages are intracellular parasites shaped by nucleic acids, such as DNA or RNA, and proteins. The protein generates a capsule, called capsid, where the nucleic acid is located. Although there are many different types of viruses developing with different behaviours when infecting cells, here we seek to replicate the specific case of phages.

One of the main characteristics of phages is the replication mechanism which follows a lytic replication process. A lytic replication process covers the following steps:

1 The virus is adhered to the border of the bacterium. It then penetrates the border and injects the cell.

2 The injected cell stops the production of its proteins, beginning to produce phage proteins, and thus starting to replicate copies of the virus nucleus-capsids. 
3 After replicating a number of nucleus-capsids, the bacterium border is broken, and new viruses are released, which can infect nearby cells.

As an alternative to the lytic replications, some viruses are capable of being lodged in cells giving rise to the lysogenic replication. A lysogenic replication operates as follow:

1 The virus infects the host cell, being lodged in its genome, where a pro-phage (mutation) can arise.

2 The virus remains hidden inside the cell for a while until it activates.

3 The replication of altered cell that contains the virus' proteins proceeds as usual. This lysogenic replication therefore produces the genome alteration of the cell resulting in a procedure similar to a mutation process.

The cell infected by phages tries to defend itself by conducting an antigenic response. In these situations, an immune response can be originated causing the development of antibodies. In such cases, the infection is stopped and the antigenic response preserves the initial conditions of the organism.

\subsection{VS: its computational equivalency}

In nature, viruses are organisms that reach their major success when infecting individuals with a low level of health (the objetive function must represent the health of the cell). The viral infection acts by means of a continuous process searching for individuals that are suitable for infection. So, viruses optimise their objetive, and infecting less healthy individuals virus are propogated.

Sometimes, when the virus infection capabilities decrease, this genetic information (solution encoding) can mutate with the intention of achieving higher levels of infection.

In this way, VS follows an exploration process that combines lytic replication to search the neighbourhood of existing solutions together with a mutation process (lysogenic replication). VS is an iterative method that runs during a maximum number of iterations, or until the optimum is reached in case of a known optimum (see Figure 1 for a schematic description of the procedure).

VS define the clinical picture of an infected population as the description of all the cells infected by viruses. Computationally, it includes the encoding of the solution that is being explored (the genome of the cell that is infected, in biological terms) and the number of nucleus-capsids being replicated, NR (for lytic replications) or the number of hidden generations, IT (for lysogenic replications). Thus the state of each virus is given by the three-tuple 'cell genome-NR-IT'. All these three-tuples corresponding to the cells infected by viruses define the clinical picture.

Therefore, when a virus infects a cell, this cell can follow a lytic or a lysogenic replication mechanism. Later, this cell could start an antigenic response depending on a pre-established probability, $p_{a n}$. Similarly, the probability of following a lytic replication is given by $p_{l t}$ and the probability of following a lysogenic replication is given by $p_{l g}$, with $p_{l t}+p_{l g}=1$.

In the case of lysogenic replications, the activation of the mutation process takes place after a limit of iterations has taken place (LIT). The value of LIT depends on the cell's health conditions, so a healthy cell (high value of the objective function being minimised, $f(x)$ ) will have a low infection probability, i.e., the value of LIT will be higher. An unhealthy cell, on the contrary, will have a lower value of LIT.

On the other hand, in case of lytic replications, $\mathrm{NR}$ is calculated for each iteration as a function of a binomial variable, $Z$, adding its value to the current NR in the clinical picture. $Z$ is calculated using a binomial distribution given by the maximum level of nucleuscapsids replicated, LNR, and the single probability of one replication, $p_{r}: Z=\operatorname{Bin}\left(L N R, p_{r}\right)$. LNR represents threshold when the cell border is broken and the viruses are released. As in the lysogenic cycle, the value of LNR is set depending on the value of the objective function being minimised, $f(x)$. Thus cells with higher values of $f(x)$ have lower probability of getting infected, and therefore the value of LNR will be higher.

VS have been proved effective, both in case of massive and selective infection (Cortés et al., 2008, 2010). In this paper, we follow a selective infection in order to maintain the computational effort bounded.

\section{Adaptation of the VS to the DDP}

The VS has been applied to a large number of combinatorial problem. However, the approach never was adapted to multi-routes problem as VRP or DDP (a specific type of VRP). This adaptation requiere the selection of an adecuate codification of the cell genome and the selecction of the mechanism of replications.

\subsection{Cell genome definition}

The possible solutions for the scheduling of daily tasks are encoded by means of an array of tasks. This array is composed of tasks and vehicles. Vehicles are represented through fictitious tasks (see Escudero et al., 2011), so the computation of the problem can be simplified.

Every vehicle must perform all tasks located to its right in the array. An example of a possible solution codification is shown in Figure 2. where three vehicles carry out ten tasks (vehicle 1: tasks 3, 2 and 4; vehicle 2: tasks 1, 5 and 6; vehicle 3: tasks 9 and 7).

Figure 2 Solution encoding

\begin{tabular}{|l|l|l|l|l|l|l|l|l|l|l|}
\hline v1 & 3 & 2 & 4 & v2 & 1 & 5 & 6 & v3 & 8 & 7 \\
\hline
\end{tabular}


Table 1 Parameter value

\begin{tabular}{lc}
\hline Parameter & Value \\
\hline$p_{l t}$ & 0.2 \\
$p_{l g}$ & 0.8 \\
$p_{a n}$ & 0.2 \\
\hline
\end{tabular}

\subsection{Evaluation of the cell health}

The cell's health (the fitness degree of the solution) is calculated depending on the number of used vehicles, the total distance covered and the breaking of time windows.

Some parameters to calculate the fitness value are:

- $c_{v}$ : fixed cost per vehicle

- $\quad c_{k m}$ : cost per unit of distance travelled

- $\quad c_{\text {miss }}$ : high fixed penalty cost if the delay results in the miss of the train or ship

- $\quad c_{\text {wait }}$ : cost per time unit due to waiting situations

- $c_{\text {depot }}$ : cost per time unit due to delays in the return to the depot.

\subsection{Particularising lytic and lysogenic replications}

As shown in Figure 1, the VS algorithm has two types of replication process: lytic and lysogenic. In the case of the DDP these replications have been developed in the following way.

Lytic replication: the neighbourhood is defined by a simple 2-opt exchange process. All the possible pairwise exchanges are considered.

Lysogenic replication: the mutation process is defined as an insertion mutation (ISM). We randomly select a task $k$, remove it from the solution and insert it randomly in a different place.

\section{Experimental results}

We tested the application of VS to the DDPTW using the same 25- and 50-task benchmark instances defined in Escudero et al. (2013). The experimentation was carried out using an Intel Core 2, and the algorithm was encoded using MATLAB 7.0.

The results of the parameter calibration process are shown in Table 1.

To analyse its performance, we compared the results of VS with several other heuristics: a saving cost heuristic ( $\mathrm{SCH})$, a nearest-neighbour heuristic (NNH), an insertion heuristic (IH) and the insertion heuristic in two phases (IH2P), developed by Caris and Janssens (2009). The results are shown in Table 2 and confirm that the VS approach outperforms classical heuristica in all the cases and improves the solution of the $\mathrm{I} 2 \mathrm{PH}$ in several cases.

Table 2 Result - total cost

\begin{tabular}{|c|c|c|c|c|c|c|}
\hline Test & N. tasks & $V S$ & $\mathrm{SCH}$ & $N N H$ & $I H$ & $I^{2} P H$ \\
\hline R1-01 & 25 & $1,075.45$ & $1,086.40$ & $1,116.17$ & $1,173.53$ & $1,084.40$ \\
\hline R1-02 & 25 & $1,033.32$ & $1,076.98$ & $1,140.61$ & $1,150.40$ & $1,131.44$ \\
\hline R1-03 & 25 & 877.82 & 918.03 & 995.97 & $1,014.22$ & 891.66 \\
\hline R1-04 & 25 & 868.57 & 913.85 & 982.19 & $1,042.86$ & 860.31 \\
\hline R1-05 & 25 & $1,053.61$ & $1,076.21$ & $1,148.50$ & $1,184.72$ & $1,054.28$ \\
\hline R1-06 & 25 & $1,011.53$ & $1,020.12$ & $1,132.77$ & $1,058.42$ & $1,010.58$ \\
\hline R1-07 & 25 & 975.73 & $1,022.27$ & $1,059.26$ & $1,077.93$ & 995.33 \\
\hline R1-08 & 25 & 941.55 & 996.01 & $1,075.57$ & $1,000.19$ & 958.25 \\
\hline R1-09 & 25 & 958.01 & 962.38 & $1,147.29$ & $1,157.50$ & 945.21 \\
\hline $\mathrm{R} 1-10$ & 25 & 911.92 & 917.67 & $1,056.01$ & $1,075.24$ & 907.54 \\
\hline R1-11 & 25 & 944.93 & 964.80 & $1,054.63$ & $1,146.42$ & 962.54 \\
\hline $\mathrm{R} 1-12$ & 25 & 938.54 & 961.15 & $1,051.14$ & $1,025.52$ & 951.15 \\
\hline R1-01 & 50 & $2,079.05$ & $2,109.29$ & $2,273.95$ & $2,418.66$ & $2,105.13$ \\
\hline R1-02 & 50 & $1,982.01$ & $1,995.82$ & $2,219.44$ & $2,418.66$ & $1,972.18$ \\
\hline R1-03 & 50 & $1,820.25$ & $1,856.86$ & $2,084.26$ & $2,013.25$ & $1,822.02$ \\
\hline R1-04 & 50 & $1,757.26$ & $1,801.87$ & $1,928.01$ & $1,996.78$ & $1,736.42$ \\
\hline R1-05 & 50 & $2,034.12$ & $2,048.44$ & $2,253.04$ & 2,299.99 & $2,059.10$ \\
\hline R1-06 & 50 & $1,885.48$ & $1,889.77$ & $2,190.66$ & $2,234.80$ & $1,892.30$ \\
\hline R1-07 & 50 & $1,806.91$ & $1,836.44$ & $2,119.90$ & $2,079.18$ & $1,852.53$ \\
\hline R1-08 & 50 & $1,736.26$ & $1,762.95$ & $1,951.68$ & $1,948.28$ & $1,741.36$ \\
\hline R1-09 & 50 & $1,873.47$ & $1,874.84$ & $2,210.75$ & $2,281.32$ & $1,880.93$ \\
\hline R1-10 & 50 & $1,845.73$ & $1,845.73$ & $2,240.97$ & $2,145.06$ & $1,833.99$ \\
\hline R1-11 & 50 & $1,882.73$ & $1,908.67$ & $2,251.20$ & $2,227.90$ & $1,871.21$ \\
\hline R1-12 & 50 & $1,780.10$ & $1,783.63$ & $2,052.04$ & $2,022.85$ & $1,763.63$ \\
\hline
\end{tabular}


Nevertheless, an additional remark must be made with respect to the computational time. The computational cost of the VS is above 15 seconds for 25 tasks and 4 minutes for 50 tasks. These times are high in comparison with those required by classical heuristics $(\mathrm{NNH}, \mathrm{SCH}$ and $\mathrm{IH})$.

These results prove that VS is a adecuate approach to routes planification, as DDP, when the time requirements are not strict.

\section{Conclusions}

The attractiveness of intermodal transport depends on the systematic reduction of costs without affecting the level of service provided. This is particularly true in the case of drayage operations, the road-base links that necessarily appear in every intermodal transport chain, and which represent a high percentage of the overall cost, since they cannot benefit from the economies of scale present in the vessel- or train-based links. The efficient planning of these drayage operations is therefore essential to improve the cost-effectiveness of the overall system while ensuring that goods suffer no unnecessary delays and that time windows are complied with.Seeking to provide a planning tool that improves the algorithms presented in other similar works, we have presented the application of a novel bio-inspired optimisation method to the daily drayage problem, which provides satisfactory results compared with the classical heuristics, and also with respect to the $\mathrm{I} 2 \mathrm{PH}$ procedure. The main conclusions to draw from our experiments are twofold. On one hand, the successful application of the virus system procedure to a completely different problem from the ones already tested in the literature reinforces the perception of VS as a sound metaheuristic methodology, overcoming the criticism that some of these new methodologies only show reasonably good performance on very specific problem instances. On the other hand, with respect to the DDP, we have shown that this novel bio-inspired technique provides further improvements to the existing solutions, thus contributing to the general cost-reduction objective.Nevertheless, although the VS presents satisfactory solutions, its computational time is higher than the one required for classical heuristics. This aspect has to be considered, especially when the VS is developed in environments where the computational time is critical, as in dynamic real time drayage systems.

\section{Acknowledgements}

This work has been (partially) supported by the Port Authority of Seville and the European Regional Development Fund under the project TECNOPORT2025 and by the challenges' programme of the statal plan of $\mathrm{I}+\mathrm{D}+\mathrm{i}$ under the project 'Ecosistema Inteligente para un Transporte de Mercancías Sostenible, Seguro e Integrado (TEC2013-47286-C3-3-R)'.

\section{References}

Braekers, K., Caris, A. and Janssens, G. (2012) 'Integrated planning of loaded and empty container movements', OR Spectrum, pp.1-22 [online] http://dx.doi.org/10.1007/s00291-012-0284-5.

Caris, A. and Janssens, G. (2009) 'A local search heuristic for the pre-and end-haulage of intermodal container terminals', Computers and Operations Research, Vol. 36, No. 10, pp.2763-2772.

Caris A, Janssens G (2010) 'A deterministic annealing algorithm for the pre-and end haulage of intermodal container terminals', International Journal of Computer Aided Engineering and Technology, Vol. 2, No. 4, pp.340-355.

Cortés, P., García, J.M., Muñuzuri, J. and Onieva, L. (2008) 'Viral systems: a new bio-inspired optimization approach', Computer \& Operation Research, Vol. 35, No. 9, pp.2840-2860.

Cortés, P., García, J.M., Muñuzuri, J. and Guadix, J. (2010) 'A viral system massive infection algorithm to solve the Steiner tree problem in graphs with medium terminal density', International Journal of Bio-Inspired Computation, Vol. 2, No. 2, pp.71-77.

Cortés, P., García, J.M., Muñuzuri, J. and Guadix, J. (2011) 'Viral system algorithm: foundations and comparison between selective and massive infections', Transactions of the Institute of Measurement and Control, Vol. 34, No. 6, pp.677-690.

Cortés, P., Onieva, L., Muñuzuri, J. and Guadix, J. (2013) 'A viral system algorithm to optimize the car dispatching in elevator group control systems of tall building', Computers \& Industrial Engineering, Vol. 64, No. 1, pp.403-411.

Dumas, Y., Desrosiers, J., Gelinas, E. and Solomon, M.M. (1995) 'An optimal algorithm for the traveling salesman problem with time windows', Operations Research, Vol. 43, No. 2, pp.367-371.

Erera, A.L. and Smilowitz, K.R. (2008) 'Intermodal drayage routing and scheduling, in P. Ioannou (Ed.): Intelligent Freight Transportation, pp.171-188, CRC Press, Taylor \& Francis Group, USA.

Escudero, A., Muñuzuri, J., Arango, C.A. and Onieva, L. (2011) 'A satellite navigation system to improve the management of intermodal drayage', Advanced Engineering Informatics, Vol. 25, No. 3, pp.427-434.

Escudero, A., Muñuzuri, J., Guadix, J. and Arango, C.A. (2013) 'Dynamic approach to solve the daily drayage problem with transit time uncertainty', Computer in Industry, Vol. 64, No. 2, pp.165-175.

Espiritu, J.F. and Ituarte-Villarreal, C.M. (2013) 'Wind farm layout optimization using a viral systems algorithm', International Journal of Applied Evolutionary Computation (IJAEC), Vol. 4, No. 4, pp.1-14.

Francis, P., Zhang, G. and Smilowitz, K.R. (2007) 'Improved modeling and solution methods for the multi-resource routing problem', European Journal of Operational Research, Vol. 180, No. 3, pp.1045-1059.

Gronalt, M., Hartl, R.F. and Reimann, M. (2003) 'New savings based algorithms for time constrained pickup and delivery of full truckloads', European Journal of Operational Research, Vol. 151, No. 3, pp.520-535. 
Imai, A., Nishimura, E. and Current, J. (2007) 'A Lagrangian relaxation-based heuristic for the vehicle routing with full container load', European Journal of Operational Research, Vol. 176, No. 1, pp.87-105.

Ituarte-Villarreal, C.M. and Espiritu, J.F. (2012) 'A viral system optimization algorithm to solve the wind farm layout problem considering reliability', 62nd IIE Annual Conference and Expo, pp.131-139.

Jula, H., Dessouky, M.M., Ioannou, P. and Chassiakos, A. (2005) 'Container movement by trucks in metropolitan networks: modeling and optimization', Transportation Research Part E, Vol. 41, No. 3, pp.235-259.

Namboothiri, R. and Erera, A.L. (2008) 'Planning local container drayage operations given a port access appointment system', Transportation Research Part E, Vol. 44, No. 2, pp.185-202.

Santosa, B. and Affandi, U. (2013) 'Application of viral systems for single-machine total weighted tardiness problem', IOP Conference Series: Materials Science and Engineering.

Smilowitz, K. (2006) 'Multi-resource routing with flexible tasks: an application in drayage operations', IIE Transactions, Vol. 38, No. 7, pp.577-590.

Suryadi, D. and Kartika, E.K. (2011) 'Viral systems application for Knapsack problem', 3rd International Conference on Computational Intelligence, Communication Systems and Networks, CICSyN, pp.11-16.
Suryadi, D., Kandi, M. and Valois, M. (2012) 'A viral systems algorithm for the traveling salesman problem', Proceedings of the International Conference on Industrial Engine.

Tan, A. and Suryadi, D. (2013) 'Viral systems imprementation for minimzing mean tardiness of job shop scheduling problem', LSCM, Bali, 26-28 June, pp.25-36.

Valles-Sosa, C.E. (2011) An Evolutionary Approach based on Viral Replication for Solving Combinatorial Optimization Problems, PhD dissertation, University of Texas at El Paso.

Zhang, R.Y., Yun, W.Y. and Moon, I. (2009) 'A reactive tabu search algorithm for the multidepot container truck transportation problem', Transportation Research Part E, Vol. 45, No. 6, pp.904-914.

Zhang, R.Y., Yun, W. and Kopfer, H. (2010) 'Heuristic-based truck scheduling for inland container transportation', OR Spectrum, Vol. 32, No. 3, pp.787-808.

Zhang, G.M., Smilowitz, K. and Erera, A. (2011) 'Dynamic planning for urban drayage operations', Transportation Research Part E, Vol. 47, No. 5, pp.764-777. 